\title{
QUEEN'S
UNIVERSITY
BELFAST
}

\section{Direct conversion of furfuryl alcohol to butyl levulinate using tin exchanged tungstophosphoric acid catalysts}

Tiwari, M. S., Dicks, J. S., Keogh, J., Ranade, V. V., \& Manyar, H. G. (2020). Direct conversion of furfuryl alcohol to butyl levulinate using tin exchanged tungstophosphoric acid catalysts. Molecular Catalysis, 488, [110918]. https://doi.org/10.1016/j.mcat.2020.110918

\section{Published in:}

Molecular Catalysis

\section{Document Version:}

Peer reviewed version

\section{Queen's University Belfast - Research Portal:}

Link to publication record in Queen's University Belfast Research Portal

\section{Publisher rights}

Copyright 2020 Elsevier.

This manuscript is distributed under a Creative Commons Attribution-NonCommercial-NoDerivs License

(https://creativecommons.org/licenses/by-nc-nd/4.0/), which permits distribution and reproduction for non-commercial purposes, provided the author and source are cited.

\section{General rights}

Copyright for the publications made accessible via the Queen's University Belfast Research Portal is retained by the author(s) and / or other copyright owners and it is a condition of accessing these publications that users recognise and abide by the legal requirements associated with these rights.

Take down policy

The Research Portal is Queen's institutional repository that provides access to Queen's research output. Every effort has been made to ensure that content in the Research Portal does not infringe any person's rights, or applicable UK laws. If you discover content in the Research Portal that you believe breaches copyright or violates any law, please contact openaccess@qub.ac.uk. 
Manuscript ID: MOLCAA-D-19-01258 Revised

\section{Direct conversion of furfuryl alcohol to butyl levulinate using tin exchanged tungstophosphoric acid catalysts}

Manishkumar S. Tiwari ${ }^{1,2}$, Jennifer Sarah Dicks ${ }^{1}$, John Keogh ${ }^{1}$, Vivek V. Ranade ${ }^{1}$ and Haresh G. Manyar ${ }^{1, *}$

${ }^{1}$ Theoretical and Applied Catalysis Research Cluster, School of Chemistry and Chemical Engineering,

Queen's University Belfast, David-Keir Building, Stranmillis Road, Belfast BT9 5AG, UK

${ }^{2}$ Department of chemical Engineering, Mukesh Patel School of Technology Management and Engineering, SVKM's NMIMS University, Mumbai 400065

Email: $\underline{\text { h.manyar@qub.ac.uk }}$

*Author to whom correspondence should be addressed 


\begin{abstract}
To decrease the dependence on crude oil, biomass derived liquid transportation fuels are highly desirable. Butyl levulinate is potential cellulose-derived biofuel additive with properties similar to diesel and low water solubility. Herein we report direct one-pot production of levulinic acid ester, butyl levulinate from furfuryl alcohol by alcoholysis using n-butanol. The partial tin exchanged tungstophosphoric acid (TPA) supported on montmorillonite K-10 catalysts showed facile alcoholysis of furfuryl alcohol to levulinate ester under mild temperature conditions. Partially, exchanging the $\mathrm{H}^{+}$ion of TPA with $\mathrm{Sn}(\mathrm{x}=1)$ resulted in enhanced acidity of the catalyst and showed an increase in the catalytic activity as compared to TPA/K-10 catalyst. A series of tin exchanged tungstophosphoric acid (20\% w/w) supported on montmorillonite $\mathrm{K}-10$ clay $\left(\mathrm{Sn}_{\mathrm{x}}-\mathrm{TPA} / \mathrm{K}-10\right.$, where $\left.\mathrm{x}=0.5-1.5\right)$ were synthesized and thoroughly characterized by using XRD, FT-IR, UV-VIS, titration and SEM techniques. Among various catalysts, $\mathrm{Sn}_{1-\mathrm{TPA}} \mathrm{K}-10$ was found to be the most active catalyst for butyl levulinate synthesis. Two different clay supports and varying tin loadings were used to study the effects on surface acidity as well as catalytic activity in butyl levulinate synthesis. Effects of different reaction parameters were studied and optimized to get high yields of butyl levulinate. Under mild reaction conditions at $110^{\circ} \mathrm{C}$, complete conversion of furfuryl alcohol with $98 \%$ selectivity to butyl levulinate was achieved. The prepared catalyst could be recycled at least five times without significant loss of activity. The overall process is green and clean.
\end{abstract}

Keywords: Butyl levulinate, furfuryl alcohol, tungstophosphoric acid, montmorillonite K-10 Heteropoly acids, biofuels 


\section{Introduction}

In recent times, the rise in energy demand and depletion of fossil fuel reserves has led to an increased attention to biomass as the potential resource for alternative energy and biofuels [1]. Apart from sustainable energy, biomass is also a key feedstock for production of a variety of value-added chemicals, which makes the biomass-derived fuel processes more economic [2-4]. To reduce the dependency on non-renewable resources, European Union and US governments have set targets to utilize renewable resources to produce up to $20 \%$ of fuel and $25 \%$ of chemicals [5]. Lignocellulosic biomass is most abundant and promising feedstock for production of chemicals and biofuels. The main components of Lignocellulosic biomass are cellulose (40-50\%), hemicellulose (25-30\%) and lignin (15-20\%) on weight basis [6,7]. Cellulose and hemicellulose can be easily converted into respective sugars, which are useful raw material to synthesise various chemicals, fuel additives and biofuels [8,9]. Alkyl levulinates $(\mathrm{AL})$ have received significant attention in recent time due to the unique properties such as stable flashpoint, high lubricity, nontoxic nature and better flow properties under cold conditions $[10,11]$ These properties make them an important value-added chemicals especially as a fuel additives $[9,12]$. Also, AL are useful to synthesize chemicals and drug intermediates, in flavors and fragrance, in plasticizer industries and as a solvent [12-17]

Particularly, butyl levulinate (BL) has high oxygen content, high octane number, low water solubility and physical properties similar to diesel $[13,18]$. BL is also used in flavours and fragrances, and is approved by the food and drug administration of the USA (FDA) [14]. The synthesis of BL can be performed using various routes starting from raw biomass, carbohydrates, levulinic acid, furfuryl alcohol and 5-hydroxymethylfurfural. Low cost of furfuryl alcohol (FAL) as compared to levulinic acid, makes direct one-pot BL synthesis from FAL lot more attractive [10]. Several homogenous and heterogenous catalyst have been reported for synthesis of BL from FAL, however a number of recyclability and environmental issues have attracted the replacement of homogeneous catalyst with heterogeneous solid acid catalysts such as sulfonic acid functionalized ionic liquids[19], $\mathrm{Al}_{2} \mathrm{O}_{3} / \mathrm{SBA}-15$ [5], Al-TUD-1 [20], double $\mathrm{SO}_{3} \mathrm{H}$-functionalized ionic liquids [21], organo-inorganic hybrid catalyst [22], ion-exchange resin [23], zinc exchanged tungstophosphoric acid supported on niobium oxide [14] and zeolites [24]. Most of these catalysts are either expensive, hard to regenerate, less active, require high catalyst to substrate ratio, or need tedious method of preparation, making it unsuitable for commercialization. 
Supported heteropoly acids (HPAs) are known to be very efficient heterogeneous catalysts for a range of acid catalysed as well as oxidation processes[25-29]. Amongst many structures of HPAs, Keggin ion, in particularTungstophshphoric acid (TPA) is found to be more acidic and active solid acid catalyst for application in various acid catalysed reactions. However all HPAs are highly soluble in polar solvents and possess poor surface areas. To overcome such limitations and achieve higher dispersion, either they are immobilised on different supports and/or protons are partially or fully substituted with metal ions [23]. Different metal ions such as $\mathrm{Cu}, \mathrm{Cs}, \mathrm{Pd}, \mathrm{Ag}, \mathrm{Al}$ and $\mathrm{Sn}$ have been used to replace the $\mathrm{H}^{+}$ions in TPA [24,25]. Different supports such as silica, alumina, titania, tin oxide, niobia oxide and K-10 have been used to make solid acid catalysts for a range of organic transformations [23,26]. Unsupported Sn exchanged TPA was prepared by Lingaiah et al and showed high activity for benzylation of arenes [34]. However, unsupported catalysts are difficult to recover, and recycle due to loss of catalytic activity upon agglomeration. K-10 with higher surface area and acidic nature is advantageous to get better dispersion of Keggin ions to improve the catalytic activity vis-a-vis unsupported HPAs.

To the best of our knowledge tin exchanged TPA as a supported catalyst for alcoholysis of furfuryl alcohol have not been explored yet. The current work aims at synthesis of tin exchanged tungstophshphoric acid supported on K-10 with different amount of tin and its activity toward synthesis of butyl levulinate (BL) from furfuryl alcohol (FAL) and 1-butanol. The catalyst was thoroughly characterised to correlate the activity of catalyst for the BL synthesis. The reaction parameters were optimized.

\section{Experimental Section}

\subsection{Chemicals}

All chemicals were of AR grade and used without any further purification. Montmorillonite K-10 clay, Tungstophosphoric acid hydrated and tin chloride were obtained from Sigma Aldrich, UK. Furfuryl alcohol, methanol and 1-butanol were procured from Alfa Aesar. All catalysts were prepared and tested in house.

\subsection{Preparation of catalyst}

All catalysts were prepared by incipient wetness impregnation method and the loading of tungstophoshphoric acid (TPA) on K-10 was 20\% w/w. Tin exchanged TPA supported on $\mathrm{K}-10$ catalysts, $20 \% \mathrm{w} / \mathrm{w} \mathrm{Sn}_{\mathrm{x}} \mathrm{H}_{3-\mathrm{x}} \mathrm{PW}_{12} \mathrm{O}_{40} / \mathrm{K}-10\left(\mathrm{Sn}_{\mathrm{x}}-\mathrm{TPA} / \mathrm{K}-10\right)$ with $\mathrm{x}$ varying from 0.5 to 1.5 were prepared in two steps of impregnation. Firstly, tin with varying amount was loaded on $\mathrm{K}-10$. Around $5 \mathrm{~g}$ of support (K-10) was dried for $3 \mathrm{~h}$ in oven at $120^{\circ} \mathrm{C}$ to remove moisture. 
The required amount of $\mathrm{Sn}(\mathrm{II}) \mathrm{Cl}_{2}$ was dissolved in methanol $(5 \mathrm{ml})$ and then added in $1 \mathrm{ml}$ quantity each time as tin precursor to dried K-10 (4 g). After each addition the solid was kneaded thoroughly to get free flowing powder. The obtained solid material was then dried at $90^{\circ} \mathrm{C}$ for $5 \mathrm{~h}$ to remove methanol. In the second step, the desired amount of TPA dissolved in methanol $(5 \mathrm{ml})$ was added to the dried powder of tin loaded K-10 clay, using same procedure as stated above to get nearly dry solid material. The resultant material was then dried at $120^{\circ} \mathrm{C}$ for $12 \mathrm{~h}$ in tubular furnace under flowing air, followed by calcination at $300^{\circ} \mathrm{C}$ for $3 \mathrm{~h}$ to get active $20 \%$ w/w $\mathrm{Sn}_{\mathrm{x}}-\mathrm{TPA} / \mathrm{K}-10$ catalyst. The resultant $20 \%$ w/w $\mathrm{Sn}_{\mathrm{x}}-\mathrm{TPA} / \mathrm{K}-10$ catalyst was stored in air tight bottle. $20 \% \mathrm{w} / \mathrm{w}$ tin exchanged TPA supported on bentonite clay catalyst was also prepared by using same method as above. $20 \%$ (w/w) TPA/K-10 catalyst was prepared by directly following the second step of the preparation method.

\subsection{Catalyst characterization}

$20 \% \mathrm{w} / \mathrm{w}$ tin exchanged TPA supported on K-10 and bentonite, and 20\% w/w TPA supported on K-10 catalysts were characterized by X-ray diffraction, framework IR, UV-Vis and SEM analyses as well as surface acidity measurement. The X-ray scattering measurements were made with PANalytical X-Pert Pro MPD diffractometer with Ni filtered $\mathrm{CuK} \alpha$ radiation $\left(1.5405 \mathrm{~A}^{\circ}\right)$. The diffractograms were recorded with step size of $0.016^{\circ}$ from $5^{\circ}$ to $80^{\circ}$. FT-IR spectra of samples were recorded on a Perkin-Elmer Fourier Transform Infrared Spectrometer. Thin transparent wafer like pellets were prepared by mixing $1 \mathrm{mg}$ of catalyst with $100 \mathrm{mg}$ of dried $\mathrm{KBr}$ and subsequent pressing.The UV-Vis spectral characterization was done using Shimadzu UV-1280 03540 spectrometer. SEM images were collected on FEI Quanta FEG 250 Scanning Electron Microscope. The acidity of prepared catalysts was measured by acid-base titration method as reported earlier [35,36]. The solid catalysts were stirred in $25 \mathrm{~mL}$ of $0.1 \mathrm{M}$ $\mathrm{NaOH}$ solution for $6 \mathrm{~h}$, and then titrated with $0.1 \mathrm{M} \mathrm{HCl}$ solution to get the acidity of samples.

\subsection{Reaction Procedure}

All the reactions were performed in $20 \mathrm{ml}$ glass reactor equipped with magnetic stirrer. Appropriate quantities of the reactants, FAL and 1-butanol were taken in a reactor and placed in oil bath at $110^{\circ} \mathrm{C}$ and agitated. Reaction mixture was stirred for 2 min at $1000 \mathrm{rpm}$ and then a zero hour sample was taken. Catalyst was added and stirring started again, the reaction was carried out for $5 \mathrm{~h}$ and samples were taken periodically for analysis. The reaction mixture was analysed by using HP-5 capillary column in Agilent 7820A GC equipped with an FID detector. The products were identified by GC-MS, synthetic mixtures were prepared and used for quantification of the data. 


\section{Results and discussion}

\subsection{Catalyst Characterization:}

\subsubsection{X-ray diffraction spectroscopy}

The X-ray diffraction patterns of all catalysts including K-10 clay, 20\% w/w TPA supported on K-10, 20\% w/w tin exchanged TPA supported K-10 with $\mathrm{x}=0.5$ to 1.5 , and reused $20 \%$ w/w $\mathrm{Sn}_{1}$ TPA supported on K-10 were recorded and are shown in Figure 1. X-ray diffraction pattern of unsupported TPA and $\mathrm{Sn}_{1}$ TPA is also shown as an insert in Figure 1. TPA and unsupported $\mathrm{Sn}_{1}$ TPA showed crystalline nature, as can be seen in the insert in Figure 1. However, peak intensity decreased after proton exchange with tin indicating the decrease in crystallinity. X-ray diffraction pattern of K-10 showed peaks at $20^{\circ}$ and $35^{\circ}$ attributed to 110 and 105 facets of montmorillonite[29,37]. Apart from that all the other peaks are due to impurities and other materials present in the K-10. This includes quartz (peak at $21.1^{\circ}, 26.5^{\circ}$, $50.1^{\circ}, 59.8^{\circ}$ ), feldspar (peak at $27.9^{\circ}$ ) and phengite (peaks at $36.6^{\circ}, 42.5^{\circ}, 45.6^{\circ}$ ), which confirms that K-10 is made of different phases as reported earlier[37-40]. X-ray diffraction patterns of TPA, and tin exchanged TPA supported on K-10 were similar to those of the corresponding K10. This could be attributed to uniform distribution of Keggin anion in the non-crystalline form because of the interaction with the surface of K-10 clay [25,29]. The X-ray diffraction pattern of reused and fresh $20 \% \mathrm{w} / \mathrm{w} \mathrm{Sn} \mathrm{Sn}_{1}$ TPA supported on K-10 catalysts were almost identical which confirmed the stability of the catalyst after reactions.




Figure 1. X-ray diffraction patterns of different catalysts (a) K-10 clay, (b) TPA/K-10,(c) $\mathrm{Sn}_{0.5-}$

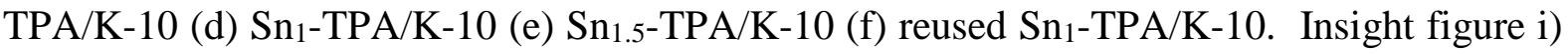
TPA, ii) Unsupported $\mathrm{Sn}_{1}$-TPA

\subsubsection{Fourier-transform infrared spectroscopy (FT-IR)}

FT-IR spectra of all catalyst samples are shown in Figure 2. It exhibits characteristic bands at 790, 891, 987 and $1081 \mathrm{~cm}^{-1}$ related to Keggin structure of TPA, assignable respectively to the stretching vibration of edge sharing $\mathrm{W}-\mathrm{O}-\mathrm{W}$, corner sharing $\mathrm{W}-\mathrm{O}-\mathrm{W}, \mathrm{W}=\mathrm{O}$ terminal and P-O bonds of Keggin ion structure in pure TPA $[19,26]$. FT-IR spectra of K-10, TPA/K-10 and tin exchanged TPA supported on K-10 were similar. The K-10 shows the intense band at $1010 \mathrm{~cm}^{-1}$ corresponding to $\mathrm{Si}-\mathrm{O}$ out of plane stretching while shoulder at 935 $\mathrm{cm}^{-1}$ is due to Si-O in-plane stretching vibration[37]. The FT-IR band in the region of $3410 \mathrm{~cm}^{-}$ ${ }^{1}$ is due to asymmetric stretching of the $-\mathrm{OH}$ group while the band in the region of 1600-1700 $\mathrm{cm}^{-1}$ corresponds to bending vibration of $-\mathrm{H}-\mathrm{O}-\mathrm{H}$ bonds[40]. All catalyst shows the same bands as corresponding to K-10 because the bands related to Keggin ion of TPA were superimposed by K-10 bands in the region of $700-1100 \mathrm{~cm}^{-1}$ as reported earlier.[41,42] FT-IR spectra of reused and fresh catalysts were also same, and no additional bands were observed. This indicates the supported Keggin anion is stable under reaction conditions.

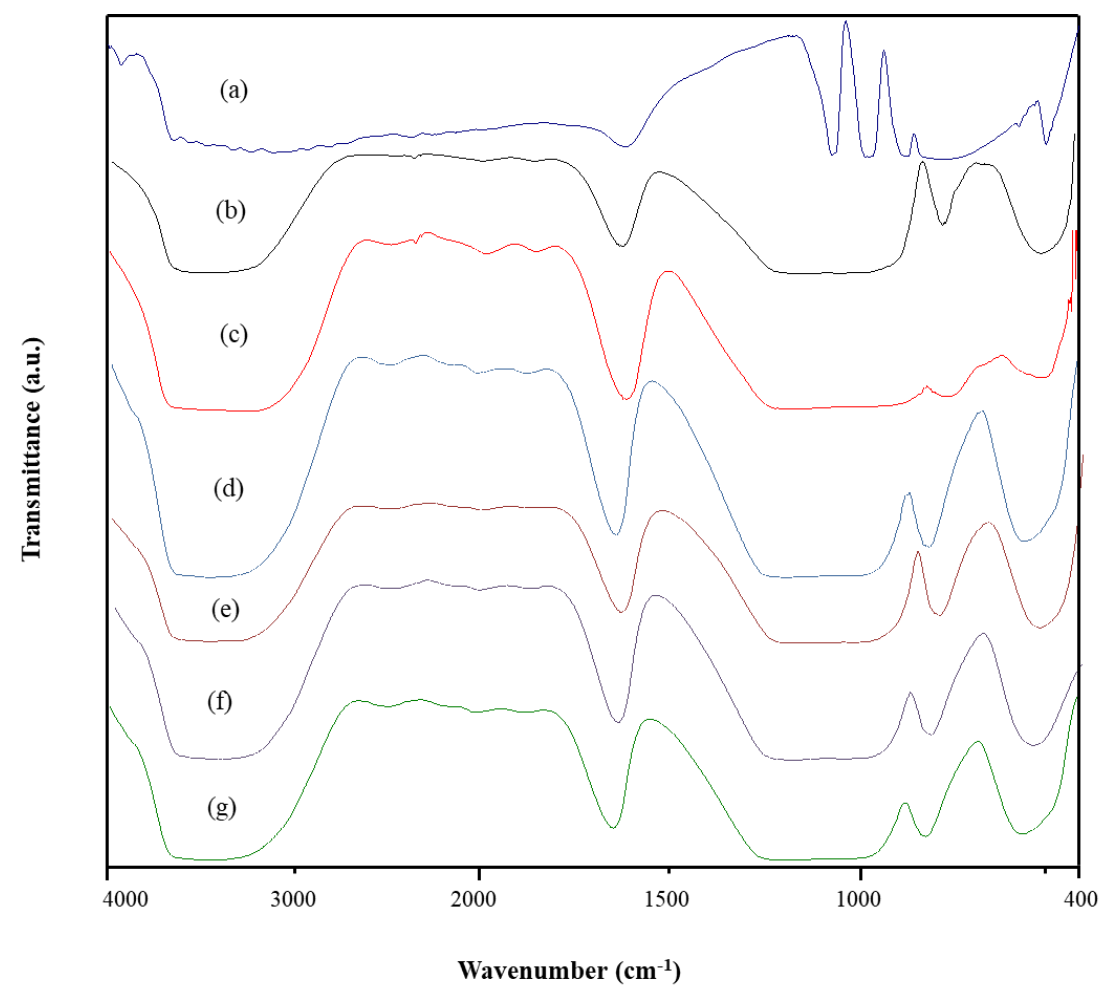


Figure 2. FT-IR spectra of catalysts (a) TPA, (b) K-10 clay, (c) TPA/K-10, (d) $\mathrm{Sn}_{0.5}-\mathrm{TPA} / \mathrm{K}-$ 10, (e) $\mathrm{Sn}_{1}-\mathrm{TPA} / \mathrm{K}-10$, (f) $\mathrm{Sn}_{1.5}-\mathrm{TPA} / \mathrm{K}-10$, and (g) reused $\mathrm{Sn}_{1}-\mathrm{TPA} / \mathrm{K}-10$.

\subsubsection{UV-VIS Spectroscopy}

UV-VIS spectra of K-10, TPA and TPA/K-10 are shown in Figure 3. K-10 showed no absorption bands indicating there is no absorbance of light. TPA showed two absorption bands at $204 \mathrm{~nm}$ and $265 \mathrm{~nm}$. These bands could be attributed to the charge transfer from terminal oxygen to tungsten and the charge transfer from bridge oxygen to metallic tungsten respectively. These bands are characteristic bands of the TPA polyanionic structure [29]. 20\% w/w $\mathrm{Sn}_{1} \mathrm{TPA} / \mathrm{K}-10$ showed the two bands which confirmed that the Keggin ion is intact and supporting TPA on K-10 does not affect the structure of TPA.

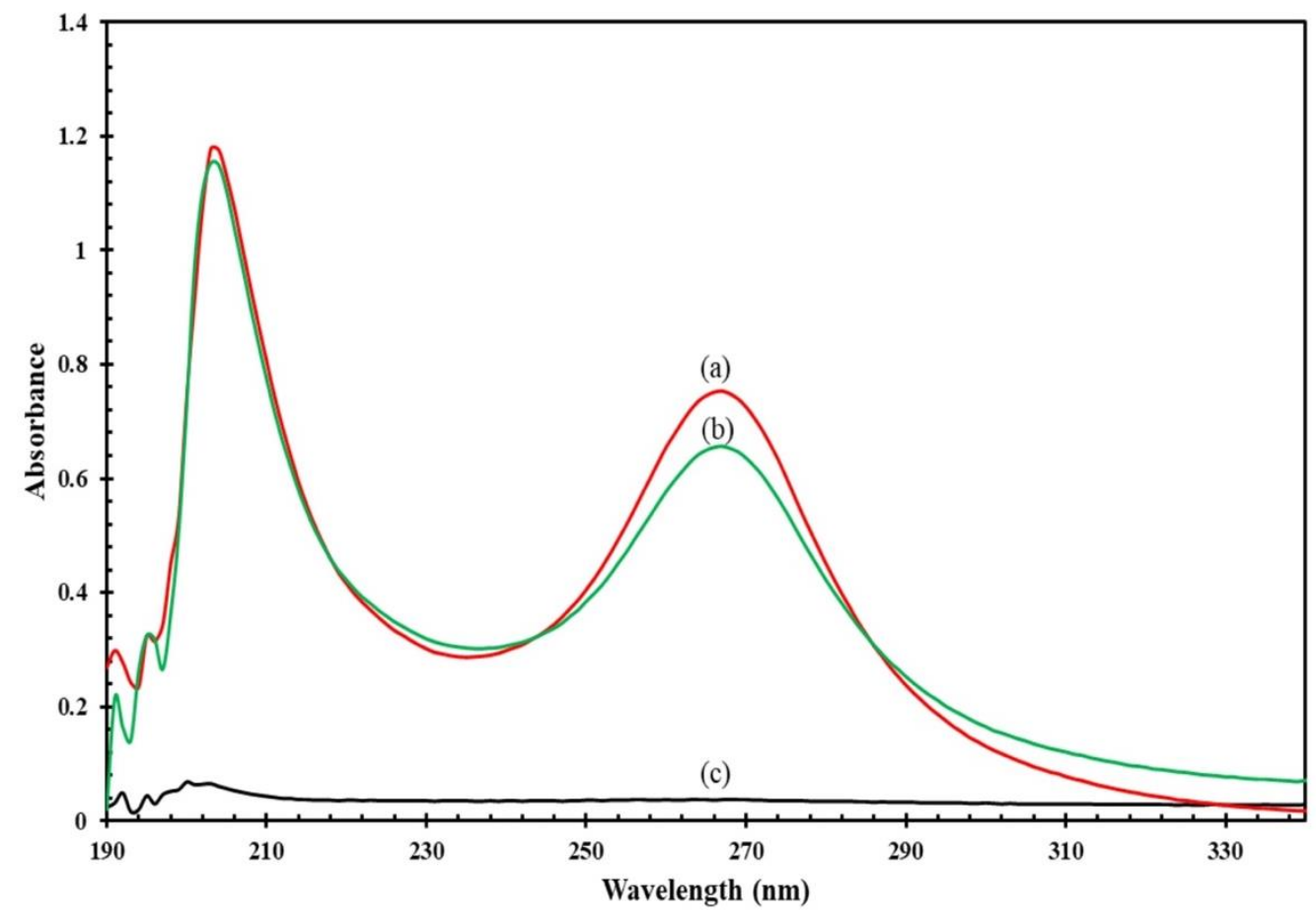

Figure 3. UV-VIS of catalysts (a) TPA, (b) $\mathrm{Sn}_{1}-\mathrm{TPA} / \mathrm{K}-10$ (c) K-10 clay

\subsubsection{SEM}

The surface morphology of the catalysts was evaluated from SEM analysis. The SEM images of $20 \% \mathrm{w} / \mathrm{w} \mathrm{Sn}_{1}-\mathrm{TPA} / \mathrm{K}-10$, fresh and reused catalyst at different magnifications are shown in Figure 4. These catalyst samples show particles of irregular morphology, which are fairly uniform in size. The images of $20 \% \mathrm{w} / \mathrm{w} \mathrm{Sn}_{1}$-TPA/K-10 show the smooth surfaces, which is similar to the K-10 [26]. The reused and fresh catalyst does not show difference in 
morphology which along with $\mathrm{x}$-ray diffraction patterns confirms the structural stability of catalyst after reuse.



(a)

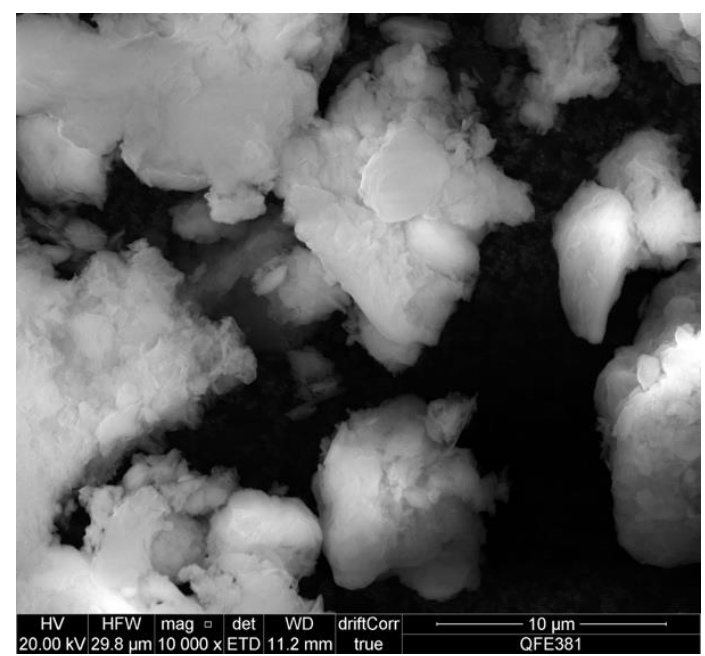

(c)

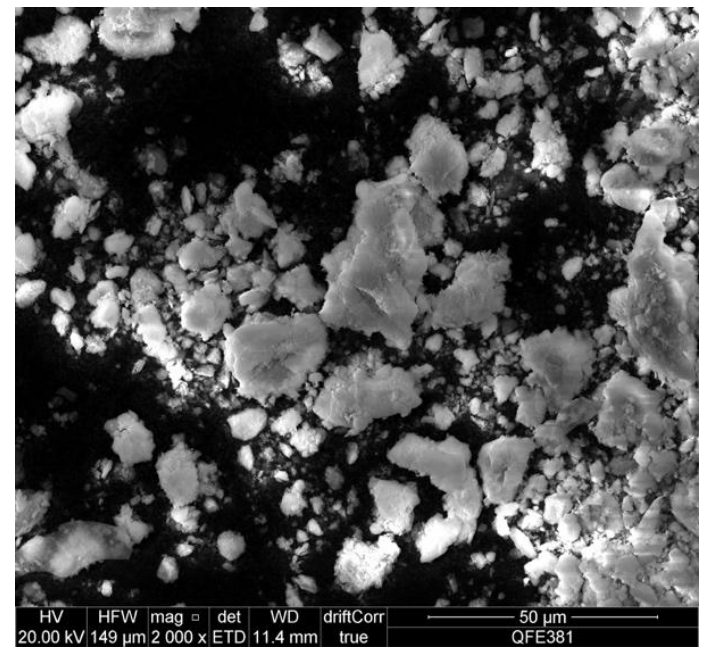

(b)

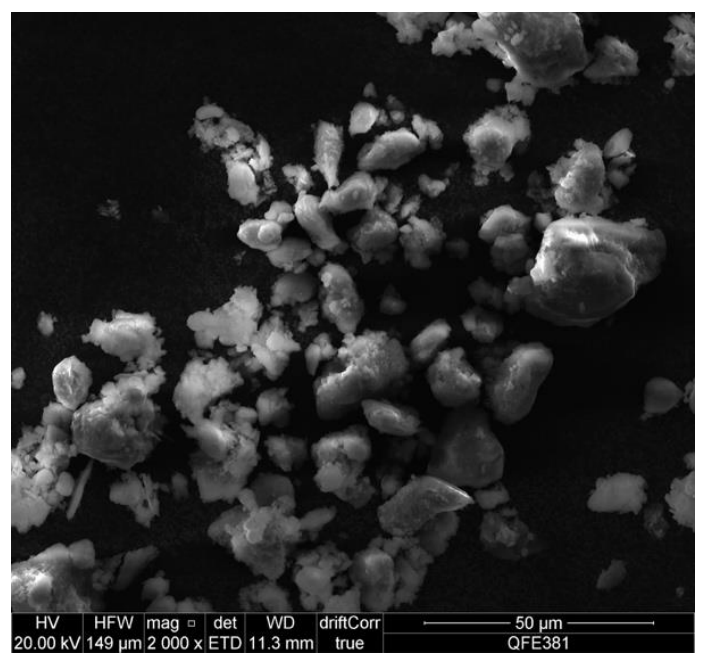

(d)

Figure 4. SEM images of fresh and recovered catalysts $(\mathrm{a}, \mathrm{b}) 20 \% \mathrm{w} / \mathrm{w} \mathrm{Sn}_{1}-\mathrm{TPA} / \mathrm{K}-10$, (c, d) reused $20 \% \mathrm{w} / \mathrm{w} \mathrm{Sn}_{1}-\mathrm{TPA} / \mathrm{K}-10$ 


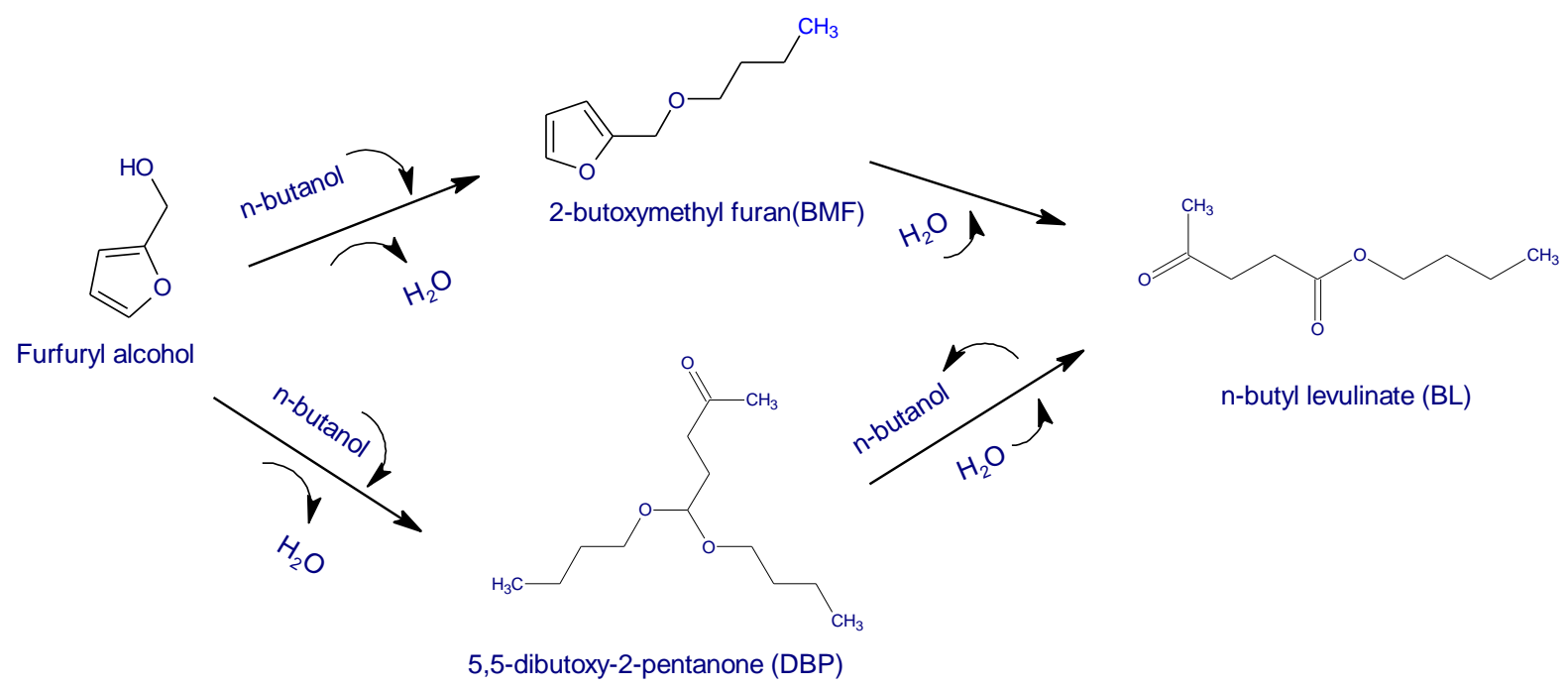

Scheme 1: Synthesis of BL from Furfuryl alcohol

\subsection{Efficacy of different solid acid catalysts}

The catalytic activity of various catalysts is compared on the basis of the \%yield of BL, since the synthesis of butyl levulinate from furfuryl alcohol is a two-step reaction. The first step is formation of intermediates, 2-butoxymethyl furan (BMF) and 5,5-dibutoxymethyl furan (DBP), which is a very fast reaction (Scheme 1). The second step, subsequent conversion of intermediates to BL, is relatively slower as compared to the first step of consumption of FAL. As reported in earlier reports $[14,15,44]$, the formation of BL can directly be corelated with activity of the catalyst hence we have considered the yield of BL as a parameter for comparison. The performance of different catalysts such as tin exchanged TPA supported on K-10, TPA supported on K-10, bentonite clay and K-10 were evaluated for butanolysis of FAL (Table 1). Two different clays as catalyst support were first used to compare their activity for butanolysis of FAL. K-10 clay as catalyst showed 100\% FAL conversion with $23.2 \%$ yield of BL in 150 min, while the use of bentonite clay catalyst resulted in $60 \%$ FAL conversion with $1.2 \%$ BL yield. The better activity of K-10 clay over bentonite clay is due to higher acidity of K-10, hence K-10 was used as catalyst support for impregnation of TPA and tin exchanged TPA.

The efficacy of different TPA supported catalyst was compared on the basis of the yield of BL as the furfuryl alcohol conversion was found to be $100 \%$ in all cases (Table 1). 20\% w/w TPA supported on K-10 showed $42.4 \%$ BL yield (entry 3), while exchange of $\mathrm{H}^{+}$ion with tin $(x=0.5)$ resulted in higher yield of BL. $20 \%$ w/w $\mathrm{Sn}_{0.5}-\mathrm{TPA} / \mathrm{K}-10$ showed $52.6 \%$ yield of BL. Further replacement of proton with $\mathrm{Sn}(\mathrm{x}=1)$ resulted in increase in overall activity of catalyst with $72.6 \%$ yield of BL at (entry 5). A subsequent increase in Sn amount up to $x=1.5$, resulted in complete removal of $\mathrm{H}^{+}$which showed lower activity (entry 6). The efficacy of 
catalysts was in following order: bentonite clay (least) $<\mathrm{K}-10<20 \% \mathrm{w} / \mathrm{w}$ TPA/K-10 $<20 \%$ w/w Sn 1.5 -TPA/K-10 < 20\% w/w Sn 0.5 -TPA/K-10 < 20\% w/w Sn 1 -TPA/K-10 (highest). The activity could directly be correlated with the acidity of catalyst as measured by titration method. The acidity of catalyst was also in the same order as the efficacy: bentonite clay (least) $<\mathrm{K}-10$ $<20 \%$ w/w TPA/K-10 < 20\% w/w Sn 1.5 -TPA/K-10 < 20\% w/w Sn 0.5 -TPA/K-10 < 20\% w/w $\mathrm{Sn}_{1.0}$-TPA/K-10 (highest). The Bronsted acidity of TPA is due to the proton conductivity in Keggin structure and exchanging the protons with metal ions results in the presence of both Bronsted as well as Lewis acidity as elucidated previously in literature.[45,46] Exchanging the protons of TPA in its secondary structure improves the proton mobility and thus increases the acidity of prepared catalyst.[46] With exchange of Sn in the secondary structure of TPA will have the same effect and hence results in increase in the acidity of catalyst as explained earlier. All further experiments for optimisation of the process conditions were carried out using $20 \%$ w/w $\mathrm{Sn}_{1}$-TPA/K-10 catalyst.

Table 1. Effect of various catalysts on conversion of furfuryl alcohol and yield of butyl levulinate.

\begin{tabular}{|c|c|c|c|c|}
\hline Entry & Catalyst & $\begin{array}{c}\text { Acidity } \\
\left(\mathrm{mmol} \mathrm{g}^{-1}\right)\end{array}$ & $\begin{array}{c}\text { FAL } \\
\text { Conversion } \\
(\%)\end{array}$ & $\begin{array}{c}\text { BL } \\
\text { Yield (\%) }\end{array}$ \\
\hline 1 & Bentonite clay & 0.24 & 60 & 1.2 \\
\hline 2 & Montmorillonite K-10 clay & 0.82 & 100 & 23.2 \\
\hline 3 & $20 \%$ w/w TPA/K-10 & 1.45 & 100 & 42.4 \\
\hline 4 & $20 \% \mathrm{w} / \mathrm{w} \mathrm{Sn}_{0.5}$-TPA/K-10 & 1.85 & 100 & 52.6 \\
\hline 5 & $20 \%$ w/w Sn $1-\mathrm{TPA} / \mathrm{K}-10$ & 2.21 & 100 & 72.6 \\
\hline 6 & $20 \%$ w/w Sn 1.5 -TPA/K-10 & 1.25 & 100 & 36.6 \\
\hline
\end{tabular}

Reaction conditions: FAL $2.3 \mathrm{mmol}$, 1-butanol $45.9 \mathrm{mmol}$, catalyst $0.9 \mathrm{~mol} \%$, temperature

$110^{\circ} \mathrm{C}$, speed of agitation $1000 \mathrm{rpm}$, reaction time $150 \mathrm{~min}$.

\subsection{Optimization of reaction parameters:}


It was desirable to study the influence of various reaction parameters on alcoholysis of FAL to optimize the process conditions for maximising the yield of BL. The results are compared on the basis of the \% yield of BL, as the conversion of FAL was always near $100 \%$ in very short reaction times.

\subsubsection{Effect of catalyst loading:}

The effect of catalyst loading was studied over a range of $0.3-1.2 \mathrm{~mol} \%$ by using $20 \% \mathrm{w} / \mathrm{w}$ $\mathrm{Sn}_{1}-\mathrm{TPA} / \mathrm{K}-10$ as catalyst. The increase in catalyst loading resulted in linear increase in the yield of BL, which is due to proportional increase in the amount of acid sites (Figure 5a). The rate of formation of $\mathrm{BL}$ was directly proportional to catalyst loading based on the mol\% of FAL, which indicates that reaction is free from external mass transfer resistance (Figure 5b). At $1.2 \mathrm{~mol} \%$ catalyst loading, maximum BL yield of $98.4 \%$ was achieved and hence this catalyst loading was used for further reactions.
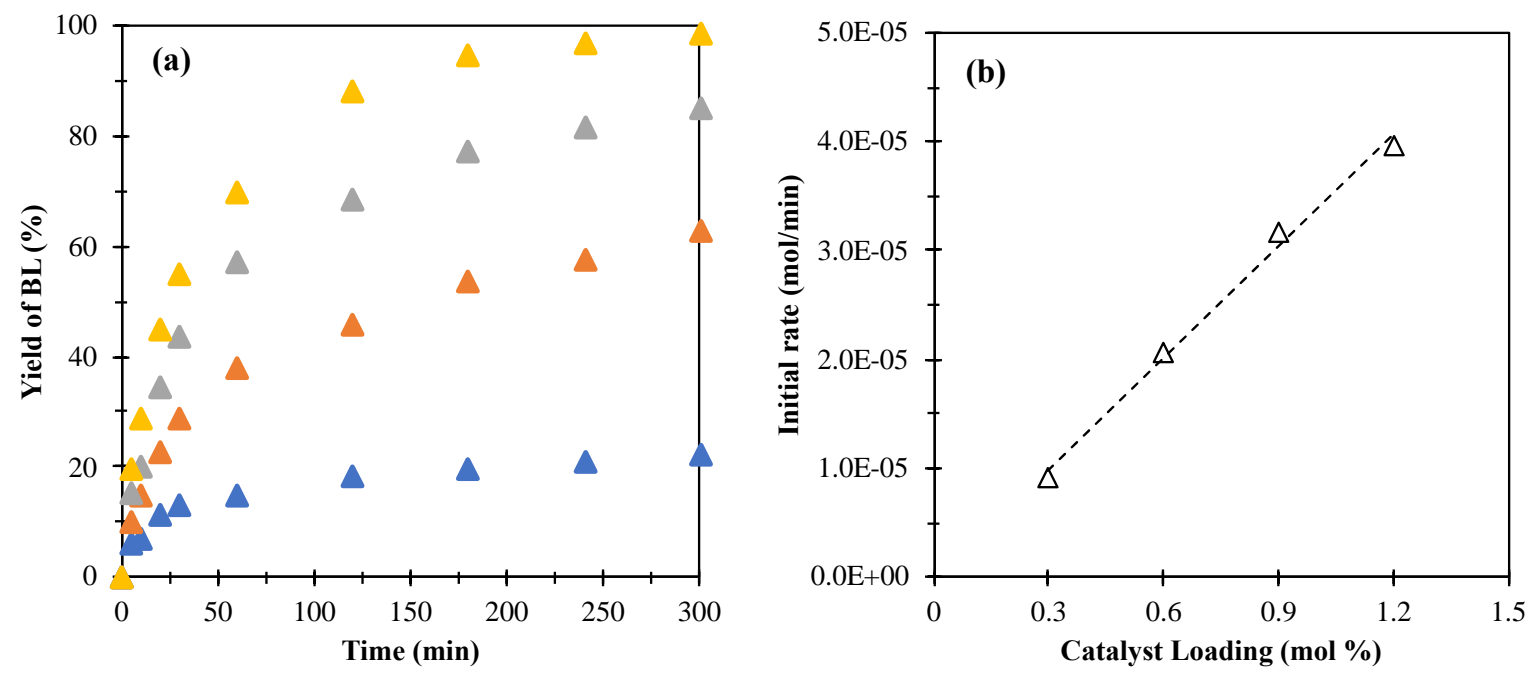

Figure 5. Effect of catalyst loading on the (a) \% yield of BL, (॰) $0.3 \mathrm{~mol} \%$, (०) $0.6 \mathrm{~mol} \%$,

(๑) $0.9 \mathrm{~mol} \%$, (॰) $1.2 \mathrm{~mol} \%$, (b) initial rate of BL formation. Reaction conditions: FAL 2.3 mmol, 1-butanol $45.9 \mathrm{mmol}, 20 \% \mathrm{w} / \mathrm{w} \mathrm{Sn}_{1}-\mathrm{TPA} / \mathrm{K}-10$ catalyst, temperature $110^{\circ} \mathrm{C}$, speed of agitation 1000 rpm, reaction time $300 \mathrm{~min}$.

\subsubsection{Effect of mole ratio}

The effect of FAL to 1-butanol mole ratio was studied over the range of 1:5 to 1:20 by using $1.2 \mathrm{~mol} \%$ of $20 \% \mathrm{w} / \mathrm{w} \mathrm{Sn}_{1}$-TPA/K-10 as catalyst maintaining other reaction parameters constant (Figure 6a). The increase in FAL:1-butanol mole ratio results in excess amount of 1butanol which acts as solvent and helps to solubilize the formed products and intermediates 
and frees the catalyst active site easily for further reaction. The reaction rate of formation of BL increased linearly with increase in FAL:1-butanol mole ratio from 1:5 to 1:20 (Figure 6b). At 1:20 mole ratio of FAL to 1-butanol, maximum yield of BL (98.4\%) was achieved, which was used as the mole ratio for further reactions.
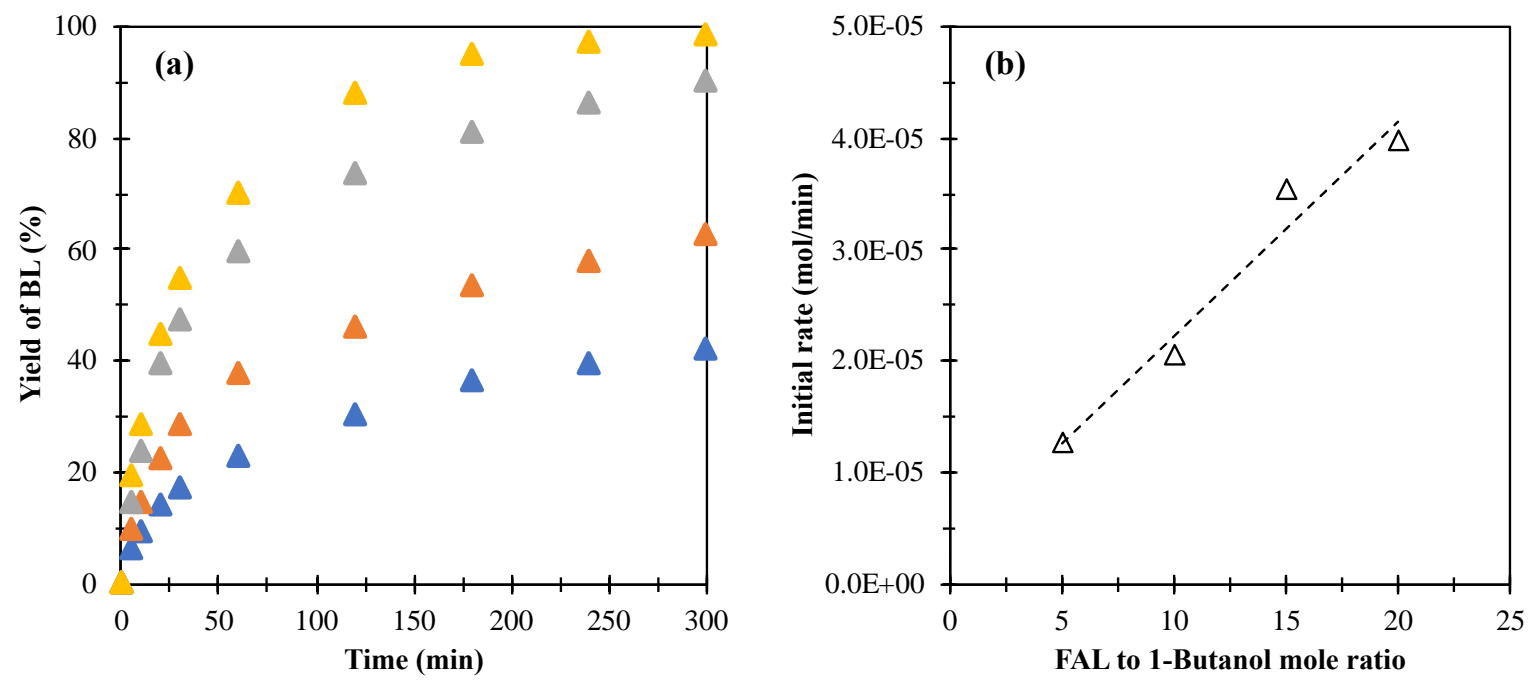

Figure 6. Effect of mole ratio of FAL to 1-butanol on the (a) \% yield of BL, (๑) 1:5, (๑) 1:10, (॰) 1:15, (॰) 1:20, (b) initial rate of BL formation. Reaction conditions: FAL, 1-butanol, 20\% $w / w S n_{1}-T P A / K-10$ catalyst 1.2 mol\%, reaction temperature $110^{\circ} \mathrm{C}$, speed of agitation 1000 rpm, reaction time 300 min.

\subsubsection{Effect of Temperature}

The effect of temperature was studied by varying the reaction temperature in the range of 90 to $120^{\circ} \mathrm{C}$ by using $1.2 \mathrm{~mol} \%$ of $20 \% \mathrm{w} / \mathrm{w} \mathrm{Sn}_{1}$-TPA/K-10 as catalyst maintaining other reaction parameters constant. The increase in temperature results in enhanced reaction rate for both steps of FAL conversion to intermediates and subsequent conversion of intermediates to $\mathrm{BL}$, indicating that the reaction is kinetically controlled and any diffusion limitation was absent. The yield of $\mathrm{BL}$ increases with increase in temperature up to $110^{\circ} \mathrm{C}$ and there after no significant change was observed in the yield of BL (Figure 7a). Hence $110^{\circ} \mathrm{C}$ was chosen as an optimum temperature for this reaction under specified condition. The activation energy for butyl levulinate formation was estimated from the Arrhenius plot using the initial rate of formation of BL (Figure 7b). The apparent activation energy for the formation of BL was found to be $36.6 \mathrm{~kJ} \mathrm{~mol}^{-1}$ using $20 \% \mathrm{w} / \mathrm{w} \mathrm{Sn}_{1}$-TPA/K-10 catalyst. The observed activation 
energy is larger than the activation energy of diffusion in liquids $\left(12-21 \mathrm{~kJ} \mathrm{~mol}^{-1}\right)$, thus confirming the absence of external mass transfer and intra-particle diffusion resistances $[47,48]$
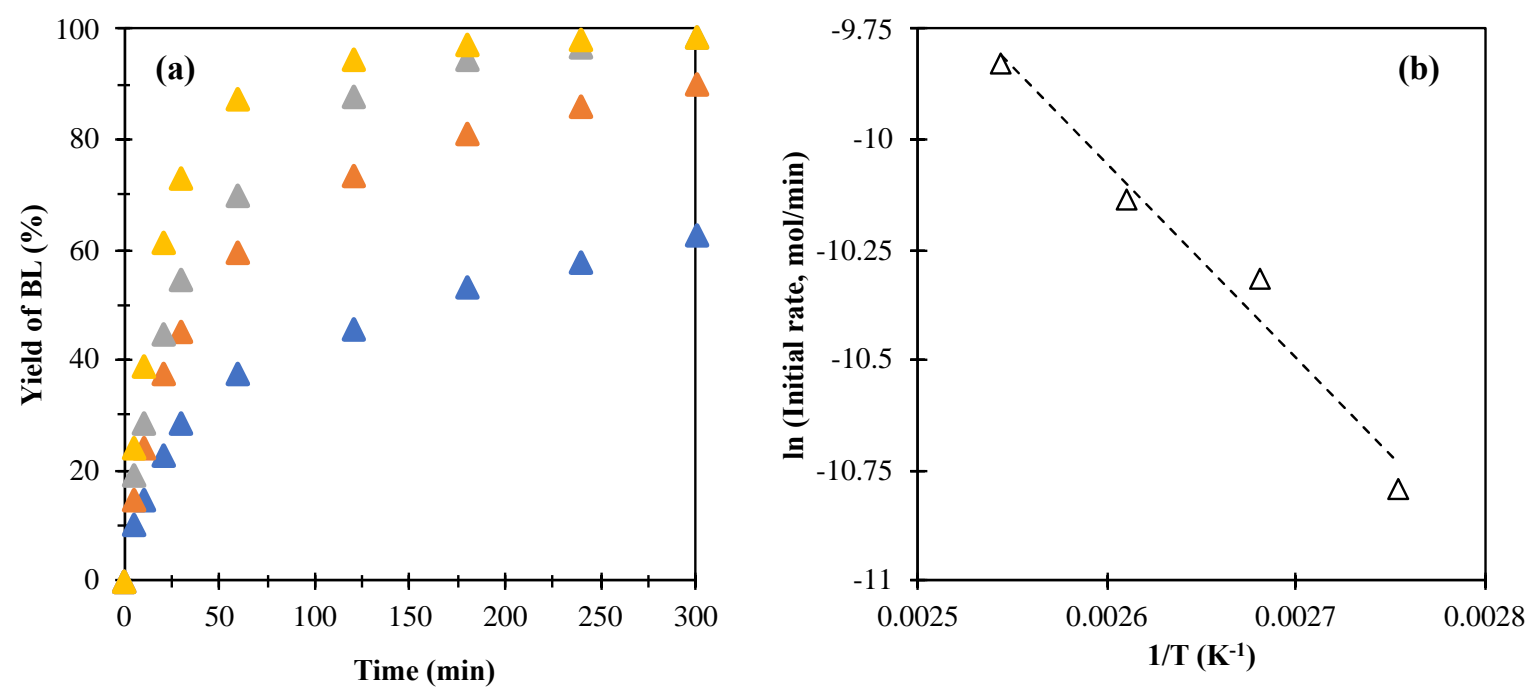

Figure 7. Effect of temperature on the (a) \% yield of BL, (॰) $90^{\circ} \mathrm{C},(\odot) 100^{\circ} \mathrm{C},(\odot) 110^{\circ} \mathrm{C},(\circ)$ $120^{\circ} \mathrm{C}$, (b) Arrhenius dependence of BL formation. Reaction conditions: FAL $2.3 \mathrm{mmol}$, 1 butanol $45.9 \mathrm{mmol}, 20 \% \mathrm{w} / \mathrm{w} \mathrm{Sn}_{1}-\mathrm{TPA} / \mathrm{K}-10$ catalyst $1.2 \mathrm{~mol} \%$, speed of agitation $1000 \mathrm{rpm}$, reaction time $300 \mathrm{~min}$.

\subsection{Comparison with solid acid catalysts}

The activity of $20 \%$ w/w Sn $\mathrm{Sn}_{1} \mathrm{TPA} / \mathrm{K}-10$ catalyst was compared with other solid acid catalysts reported in literature for BL synthesis from FAL to compare the catalyst performance with the state-of-the-art catalysts (Table 2). However, the comparison was only semiquantitative, since in many cases the reaction conditions applied are far from optimum. The activity of catalysts was compared on the basis of the \% yield of BL after $3 \mathrm{~h}$. Tin exchanged TPA supported on K-10 is highly active as compared to most catalysts with $97.5 \%$ yield of $\mathrm{BL}$ in $3 \mathrm{~h}$. The result is indicative of the better efficacy of $20 \% \mathrm{w} / \mathrm{w} \mathrm{Sn}_{1}-\mathrm{TPA} / \mathrm{K}-10$ catalyst for conversion of FAL to BL.

\subsection{Catalyst reusability and heterogeneity:}

The catalyst reusability was studied five times under optimum reaction conditions (Figure 8a). After the reaction catalyst was filtered, and washed with acetone under reflux. The colour of catalyst was black after recovery, which changed to dark brown upon washing. The washed catalyst was subsequently calcined at $300{ }^{\circ} \mathrm{C}$ before being reused in subsequent batches. In presence of the fresh $20 \%$ w/w $\mathrm{Sn}_{1}-\mathrm{TPA} / \mathrm{K}-10$ catalyst, the BL yield was $98.4 \%$. During the 
$5^{\text {th }}$ cycle, BL yield decreased to $93.6 \%$, which may be attributed to chemical adsorption of reactants or intermediates, as indicated from the colour of the catalyst. Reused catalyst was characterized using different techniques and found to be same in the nature as the fresh catalyst, indicating that the catalyst is stable and reusable.

Table 2: Comparison of different solid acid catalysts for BL synthesis after $3 \mathrm{~h}$

\begin{tabular}{|c|c|c|c|c|c|c|c|}
\hline No. & $\begin{array}{l}\text { Mole } \\
\text { ratio }\end{array}$ & Catalyst & $\begin{array}{l}\text { Cat. } \\
\text { Amt. }\end{array}$ & $\mathrm{T}\left({ }^{\circ} \mathrm{C}\right)$ & $\mathrm{X}(\%)$ & $\mathrm{Y}(\%)$ & Ref \\
\hline 1 & $1: 65$ & $\mathrm{Zn}_{1} \mathrm{TPA} / \mathrm{Nb}_{2} \mathrm{O}_{5}$ & $0.3 \mathrm{~g}$ & 110 & 100 & 91 & [14] \\
\hline 2 & $1: 33$ & SBA-15- $\mathrm{SO}_{3} \mathrm{H}$ & $0.5 \mathrm{~g}$ & 110 & 100 & 92 & {$[15]$} \\
\hline 3 & $1: 60$ & 100Ti-KIT-6 & $0.3 \mathrm{~g}$ & 110 & 90 & 72 & [49] \\
\hline 4 & $1: 65$ & 25TS/SBA-16 & $0.3 \mathrm{~g}$ & 110 & 100 & 97 & {$[13]$} \\
\hline 5 & $1: 8$ & Amberlyst 39 & $1 \mathrm{~g}$ & 110 & 99 & 52 & [23] \\
\hline 6 & $1: 15$ & $\mathrm{KCC}-1 / \mathrm{Pr}-\mathrm{SO}_{3} \mathrm{H}$ & $0.1 \mathrm{~g}$ & 120 & 99 & 81.9 & {$[44]$} \\
\hline 7 & $1: 48$ & {$[\mathrm{MIMBS}]_{3} \mathrm{PW}_{12} \mathrm{O}_{40}$} & $0.2 \mathrm{~g}$ & 110 & 99 & 78 & {$[22]$} \\
\hline 8 & $1: 48$ & h-Y Zeolite & $0.03 \mathrm{~g}$ & 110 & 100 & N.R. & {$[22]$} \\
\hline 9 & $1: 33$ & HZSM-5 & $0.05 \mathrm{~g}$ & 110 & 100 & 33 & {$[15]$} \\
\hline 10 & $1: 65$ & $20 \mathrm{Al}_{2} \mathrm{O}_{3} / \mathrm{SBA}-15$ & $0.4 \mathrm{~g}$ & 110 & 100 & 60 & {$[5]$} \\
\hline 11 & $1: 20$ & $\mathrm{Sn}_{1} \mathrm{TPA} / \mathrm{K}-10$ & $0.4 \mathrm{~g}$ & 120 & 100 & 97.5 & $\begin{array}{l}\text { This } \\
\text { work }\end{array}$ \\
\hline
\end{tabular}

$X=\%$ conversion of FAL, $Y=\%$ Yield of BL after $3 h, N . R .=$ not reported

A further proof of TPA stability on K-10 clay was obtained by a control experiment. The reaction mixture consisted of FAL $(2.3 \mathrm{mmol})$ and 1-butanol $(45.9 \mathrm{mmol})$ with standard catalyst loading of $0.4 \mathrm{~g}$ of $20 \% \mathrm{w} / \mathrm{w} \mathrm{Sn}_{1}-\mathrm{TPA} / \mathrm{K}-10$, alcoholysis was performed at $110{ }^{\circ} \mathrm{C}$, for 30 minutes. A BL yield of $54.6 \%$ was achieved. The reaction mixture was hot filtered, and all catalyst particles were separated. The reaction was further continued at $110{ }^{\circ} \mathrm{C}$, for next 4 hours 
without any catalyst. There was a slight increase in yield of BL from 54.6\% to 55.8\% (Figure 8b). The test was performed 3 times with fresh catalyst and each time there was a very slight change noticed either decrease or increase but limited within $\pm 1 \%$, which is within experimental error. Thus it is concluded, that Sn exchanged TPA was strongly adsorbed on K10 clay, and catalyst is stable under reaction conditions.
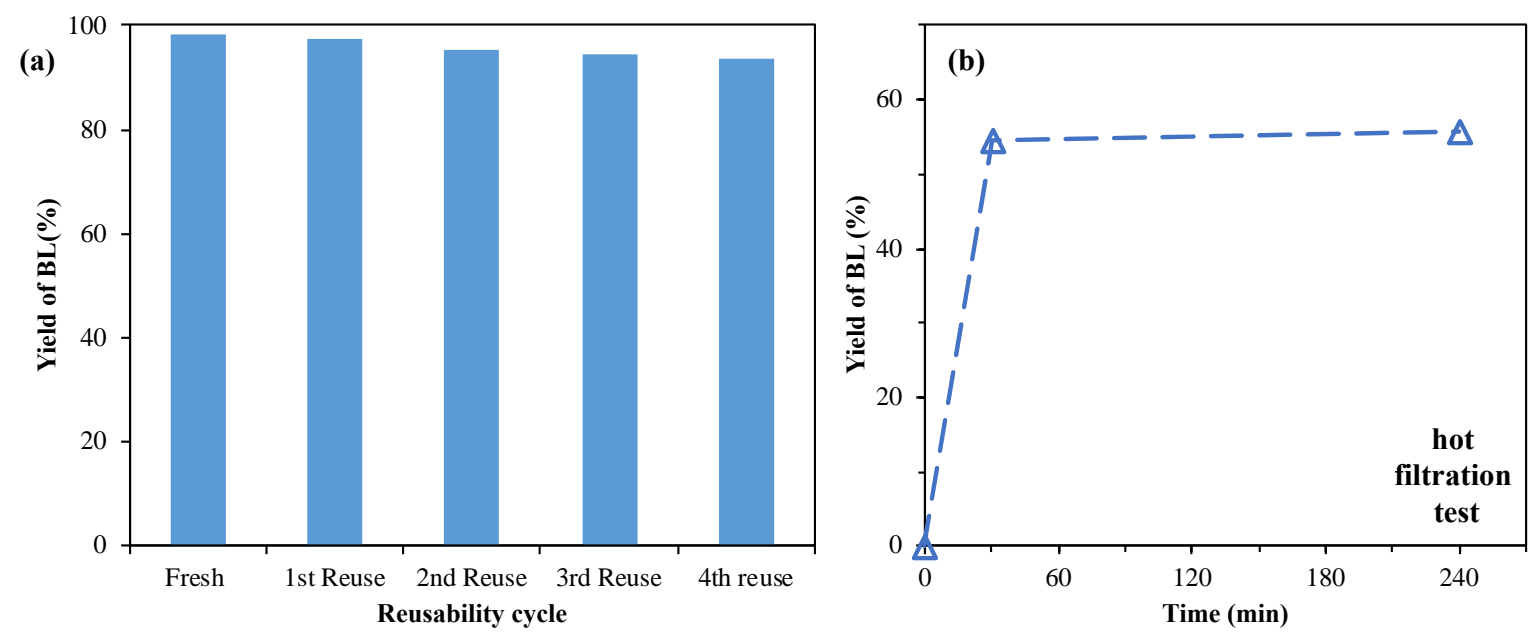

Figure 8. (a) Effect of catalyst reusability on the \% yield of BL, (b) Evaluation of stability of $20 \%$ w/w $\mathrm{Sn}_{1}$-TPA on K-10. Reaction conditions: FAL $2.3 \mathrm{mmol}$, 1-butanol 45.9 mmol, $20 \%$ w/w Sn $\mathrm{Sn}_{1}$ TPA/K-10 catalyst $1.2 \mathrm{~mol} \%$, speed of agitation $1000 \mathrm{rpm}$, reaction temperature 110 ${ }^{\circ} \mathrm{C}$, reaction time $300 \mathrm{~min}$.

\section{Conclusions}

Various tin exchanged tungstophosphoric acid supported on K-10 catalysts with intact Keggin ion structure were prepared. Sn exchanged catalysts were found to be highly active for synthesis of butyl levulinate from alcoholysis of FAL with 1-butanol. The amount of Sn exchanged, and type of clay control the acidity of catalyst and hence the activity of catalyst. $20 \% \mathrm{w} / \mathrm{w} \mathrm{Sn}_{1}$-TPA/K-10 catalyst was found to be most active catalyst. The reaction parameters, $1.2 \mathrm{~mol} \% 20 \% \mathrm{w} / \mathrm{w} \mathrm{Sn}_{1}$-TPA/K-10 catalyst loading, reaction temperature $110{ }^{\circ} \mathrm{C}$, speed of agitation 1000 RPM and FAL to 1-butanol mole ratio of 1:20, resulted in complete conversion of FAL, with maximum yield (98.4\%) of BL. The $20 \%$ w/w Sn 1 -TPA/K-10 catalyst exhibited good reusability over 5 recycles, without significant loss of activity. The catalyst activity was compared with reported literature and found to be highly active catalyst. 


\section{Acknowledgment}

The authors gratefully acknowledge the financial support from the Invest Northern Ireland Competence Centre programme under the "Centre for Advanced Sustainable Energy" (CASE) project R3947CCE for postdoctoral funding for MT, Department for the Economy (DfE) for PhD studentship to JD and "The Bryden centre for advanced marine and bio-energy research" project for PhD studentship to JK. The Bryden Centre project is supported by the European Union's INTERREG VA Programme, managed by the Special EU Programmes Body (SEUPB).

\section{Disclaimer:}

The views and opinions expressed in this report/document/poster/paper (delete as appropriate) do not necessarily reflect those of the European Commission or the Special EU Programmes Body (SEUPB).

\section{Acronyms}

K-10 Montmorillonite clay

TPA Tungstophosphoric acid i.e. $\mathrm{H}_{3} \mathrm{PW}_{12} \mathrm{O}_{40}$

$\mathrm{Sn}_{\mathrm{x}}-\mathrm{TPA} / \mathrm{K}-10 \quad \mathrm{Sn}_{\mathrm{x}} \mathrm{H}_{(3-\mathrm{x})} \mathrm{PW}_{12} \mathrm{O}_{40}$ supported on montmorillonite $\mathrm{K}-10$ clay

\section{References}

[1] E. Ahmad, I. Alam, K.K. Pant, M.A. Haider, Catalytic and mechanistic insights into the production of ethyl levulinate from biorenewable feedstocks, Green Chem. 18 (2016) 4804-4823. doi:10.1039/c6gc01523a.

[2] K.Y. Nandiwale, A.M. Pande, V. V Bokade, HPW Anchored Meso-HZ-5 , a Novel Catalyst for Selective Synthesis of Ethyl Levulinate Biofuel by Alcoholysis of Biomass-Derived Furfuryl Alcohol, 00 (2017) 1-7. doi:10.1002/ep.12822.

[3] Y. Chen, F. Wang, Y. Jia, N. Yang, X. Zhang, One-step ethanolysis of lignin into small-molecular aromatic hydrocarbons over nano-SiC catalyst, Bioresour. Technol. 226 (2017) 145-149. doi:10.1016/j.biortech.2016.12.008.

[4] J. Molleti, M.S. Tiwari, G.D. Yadav, Novel synthesis of Ru/OMS catalyst by solvent- 
free method: Selective hydrogenation of levulinic acid to $\gamma$-valerolactone in aqueous medium and kinetic modelling, Chem. Eng. J. 334 (2018) 2488-2499. doi:10.1016/j.cej.2017.11.125.

[5] S.S. Enumula, K.S. Koppadi, V. Ramesh, B. Gurram, D.R. Burri, S. Rama, R. Kamaraju, Sustainable Energy \& Fuels, Sustain. Energy Fuels. 1 (2017) 644-651. doi:10.1039/C6SE00103C.

[6] R. Reddy, C. Kumara, S. Koppadi, S. Sankar, E. Murali, Continuous Synthesis of Fuel Additives Alkyl Levulinates via Alcoholysis of Furfuryl Alcohol over Silica Supported Metal Oxides, Catal. Letters. 0 (2018) 0. doi:10.1007/s10562-018-2371-y.

[7] A.B. Gawade, M.S. Tiwari, G.D. Yadav, Biobased Green Process: Selective Hydrogenation of 5-Hydroxymethylfurfural to 2,5-Dimethyl Furan under Mild Conditions Using Pd-Cs 2.5 H 0.5 PW 12 O 40 /K-10 Clay, ACS Sustain. Chem. Eng. 4 (2016) 4113-4123. doi:10.1021/acssuschemeng.6b00426.

[8] J. Cui, J. Tan, T. Deng, X. Cui, H. Zheng, Y. Zhu, Y. Li, Direct conversion of carbohydrates to $\gamma$-valerolactone facilitated by a solvent effect, Green Chem. 17 (2015) 3084-3089. doi:10.1039/C5GC00110B.

[9] Y.-B. Huang, T. Yang, M.-C. Zhou, H. Pan, Y. Fu, Microwave-assisted alcoholysis of furfural alcohol into alkyl levulinates catalyzed by metal salts, Green Chem. 18 (2016) 1516-1523. doi:10.1039/C5GC01581B.

[10] M.S. Tiwari, A.B. Gawade, G.D. Yadav, Magnetically separable sulfated zirconia as highly active acidic catalysts for selective synthesis of ethyl levulinate from furfuryl alcohol, Green Chem. 19 (2017) 963-976. doi:10.1039/C6GC02466A.

[11] Y. Wang, D. Zhao, K.S. Triantafyllidis, W. Ouyang, R. Luque, C. Len, Microwaveassisted catalytic upgrading of bio-based furfuryl alcohol to alkyl levulinate over commercial non-metal activated carbon, Mol. Catal. 480 (2020) 110630. doi:10.1016/j.mcat.2019.110630.

[12] D. Zhao, P. Prinsen, Y. Wang, W. Ouyang, F. Delbecq, C. Len, R. Luque, Continuous Flow Alcoholysis of Furfuryl Alcohol to Alkyl Levulinates Using Zeolites, ACS Sustain. Chem. Eng. 6 (2018) 6901-6909. doi:10.1021/acssuschemeng.8b00726.

[13] E. Siva, S.K. Saidulu, R. Yadagiri, J. Burri, D. Raju, Alcoholysis of Furfuryl Alcohol into n -Butyl Levulinate Over SBA-16 Supported Heteropoly Acid Catalyst, Catal. Letters. 147 (2017) 2807-2816. doi:10.1007/s10562-017-2155-9.

[14] B.S. Rao, P.K. Kumari, D. Dhanalakshmi, N. Lingaiah, Selective conversion of furfuryl alcohol into butyl levulinate over zinc exchanged heteropoly tungstate 
supported on niobia catalysts, Mol. Catal. 427 (2017) 80-86.

doi:10.1016/j.molcata.2016.11.032.

[15] P.D. Carà, R. Ciriminna, N.R. Shiju, G. Rothenberg, Enhanced Heterogeneous Catalytic Conversion of Furfuryl Alcohol into Butyl Levulinate, (2014) 835-840. doi:10.1002/cssc.201301027.

[16] W. Ouyang, D. Zhao, Y. Wang, A.M. Balu, C. Len, R. Luque, Continuous Flow Conversion of Biomass-Derived Methyl Levulinate into $\gamma$-Valerolactone Using Functional Metal Organic Frameworks, ACS Sustain. Chem. Eng. 6 (2018) 67466752. doi:10.1021/acssuschemeng.8b00549.

[17] D. Zhao, Y. Wang, F. Delbecq, C. Len, Continuous flow conversion of alkyl levulinates into $\gamma$-valerolactone in the presence of $\mathrm{Ru} / \mathrm{C}$ as catalyst, Mol. Catal. 475 (2019) 110456. doi:10.1016/j.mcat.2019.110456.

[18] S. Dharne, V.V. Bokade, Esterification of levulinic acid to n-butyl levulinate over heteropolyacid supported on acid-treated clay, J. Nat. Gas Chem. 20 (2011) 18-24. doi:10.1016/S1003-9953(10)60147-8.

[19] A.M. Hengne, S.B. Kamble, C. V. Rode, Single pot conversion of furfuryl alcohol to levulinic esters and $\gamma$-valerolactone in the presence of sulfonic acid functionalized ILs and metal catalysts, Green Chem. 15 (2013) 2540. doi:10.1039/c3gc41098f.

[20] P. Neves, M.M. Antunes, P.A. Russo, J.P. Abrantes, S. Lima, A. Fernandes, M. Pillinger, S.M. Rocha, M.F. Ribeiro, A.A. Valente, Production of biomass-derived furanic ethers and levulinate esters using heterogeneous acid catalysts, Green Chem. 15 (2013) 3367. doi:10.1039/c3gc41908h.

[21] G. Wang, Z. Zhang, L. Song, Efficient and selective alcoholysis of furfuryl alcohol to alkyl levulinates catalyzed by double SO $3 \mathrm{H}$-functionalized ionic liquids, Green Chem. 16 (2014) 1436-1443. doi:10.1039/C3GC41693C.

[22] Z. Zhang, K. Dong, Z.K. Zhao, Efficient Conversion of Furfuryl Alcohol into Alkyl Levulinates Catalyzed by an Organic-Inorganic Hybrid Solid Acid Catalyst, ChemSusChem. 4 (2011) 112-118. doi:10.1002/cssc.201000231.

[23] R. Bringué, E. Ramírez, M. Iborra, J. Tejero, F. Cunill, Esterification of furfuryl alcohol to butyl levulinate over ion-exchange resins, Fuel. 257 (2019) 116010. doi:10.1016/j.fuel.2019.116010.

[24] H.A. Al-Lohedan, J.J. Vijaya, J.N. Appaturi, M.R. Johan, R.J. Ramalingam, H.A. AlLohedan, J.J. Vijaya, Efficient synthesis of butyl levulinate from furfuryl alcohol over ordered mesoporous Ti-KIT-6 catalysts for green chemistry applications, RSC Adv. 7 
(2017) 55206-55214. doi:10.1039/C7RA10289E.

[25] M.S. Tiwari, G.D. Yadav, Kinetics of Friedel-Crafts benzoylation of veratrole with benzoic anhydride using Cs2.5H0.5PW12O40/K-10 solid acid catalyst, Chem. Eng. J. 266 (2015) 64-73. doi:10.1016/j.cej.2014.12.043.

[26] G.D. Yadav, H.G. Manyar, Novelties of synthesis of acetoveratrone using heteropoly acid supported on hexagonal mesoporous silica, Microporous Mesoporous Mater. 63 (2003) 85-96. doi:10.1016/S1387-1811(03)00434-7.

[27] H.G. Manyar, G.S. Chaure, A. Kumar, Supported polyperoxometallates: Highly selective catalyst for oxidation of alcohols to aldehydes, J. Mol. Catal. A Chem. 243 (2006) 244-252. doi:10.1016/j.molcata.2005.09.036.

[28] S. Doherty, J.G. Knight, J.R. Ellison, D. Weekes, R.W. Harrington, C. Hardacre, H. Manyar, An efficient recyclable peroxometalate-based polymer-immobilised ionic liquid phase (PIILP) catalyst for hydrogen peroxide-mediated oxidation, Green Chem. 14 (2012) 925. doi:10.1039/c2gc16679h.

[29] M.S. Tiwari, G.D. Yadav, Novel aluminium exchanged dodecatungstophosphoric acid supported on K-10 clay as catalyst: benzoylation of diphenyloxide with benzoic anhydride, RSC Adv. 6 (2016) 49091-49100. doi:10.1039/C6RA05379C.

[30] G.S. Armatas, G. Bilis, M. Louloudi, Highly ordered mesoporous zirconiapolyoxometalate nanocomposite materials for catalytic oxidation of alkenes, J. Mater. Chem. 21 (2011) 2997. doi:10.1039/c0jm03395b.

[31] C.R. Kumar, K. Jagadeeswaraiah, P.S.S. Prasad, N. Lingaiah, Samarium-exchanged Heteropoly Tungstate: An Efficient Solid Acid Catalyst for the Synthesis of Glycerol Carbonate from Glycerol and Benzylation of Anisole, ChemCatChem. 4 (2012) 13601367. doi:10.1002/cctc.201200110.

[32] K. Shimizu, K. Niimi, A. Satsuma, Polyvalent-metal salts of heteropolyacid as efficient heterogeneous catalysts for Friedel-Crafts acylation of arenes with carboxylic acids, Catal. Commun. 9 (2008) 980-983. doi:10.1016/j.catcom.2007.09.030.

[33] M.S. Tiwari, T. Jain, G.D. Yadav, Novel Bifunctional PalladiumDodecatungstophosphoric Acid Supported on Titania Nanotubes : One-Pot Synthesis of n - Pentyl Tetrahydrofurfuryl Ether from Furfuryl Alcohol and n - Pentanol, (2017) 12909-12919. doi:10.1021/acs.iecr.7b00078.

[34] C. Ramesh Kumar, K.T.V. Rao, P.S. Sai Prasad, N. Lingaiah, Tin exchanged heteropoly tungstate: An efficient catalyst for benzylation of arenes with benzyl alcohol, J. Mol. Catal. A Chem. 337 (2011) 17-24. doi:10.1016/j.molcata.2011.01.008. 
[35] A. de N. de Oliveira, M.A. Barbosa de Lima, L.H. de Oliveira Pires, M. Rosas da Silva, P.T. Souza da Luz, R.S. Angélica, G.N. da Rocha Filho, C.E. F. da Costa, R. Luque, L.A. Santos do Nascimento, Bentonites Modified with Phosphomolybdic Heteropolyacid (HPMo) for Biowaste to Biofuel Production, Materials (Basel). 12 (2019) 1431. doi:10.3390/ma12091431.

[36] L.R. V. da Conceição, L.M. Carneiro, D.S. Giordani, H.F. de Castro, Synthesis of biodiesel from macaw palm oil using mesoporous solid catalyst comprising 12molybdophosphoric acid and niobia, Renew. Energy. 113 (2017) 119-128. doi:10.1016/j.renene.2017.05.080.

[37] F.-F. Wang, J. Liu, H. Li, C.-L. Liu, R.-Z. Yang, W.-S. Dong, Conversion of cellulose to lactic acid catalyzed by erbium-exchanged montmorillonite K10, Green Chem. 17 (2015) 2455-2463. doi:10.1039/C4GC02131B.

[38] A.C. Garade, V.S. Kshirsagar, R.B. Mane, A.A. Ghalwadkar, U.D. Joshi, C.V. Rode, Acidity tuning of montmorillonite K10 by impregnation with dodecatungstophosphoric acid and hydroxyalkylation of phenol, Appl. Clay Sci. 48 (2010) 164-170. doi:10.1016/j.clay.2009.11.042.

[39] M. Ayoub, A.Z. Abdullah, LiOH-modified montmorillonite K-10 as catalyst for selective glycerol etherification to diglycerol, Catal. Commun. 34 (2013) 22-25. doi:10.1016/j.catcom.2013.01.007.

[40] G.B.B. Varadwaj, S. Rana, K. Parida, B.B. Nayak, A multi-functionalized montmorillonite for co-operative catalysis in one-pot Henry reaction and water pollution remediation, J. Mater. Chem. A. 2 (2014) 7526. doi:10.1039/c4ta00042k.

[41] M.S. Tiwari, G.D. Yadav, Kinetics of Friedel-Crafts benzoylation of veratrole with benzoic anhydride using Cs2.5H0.5PW12O40/K-10 solid acid catalyst, Chem. Eng. J. 266 (2015). doi:10.1016/j.cej.2014.12.043.

[42] M.S. Tiwari, G.D. Yadav, Novel aluminium exchanged dodecatungstophosphoric acid supported on K-10 clay as catalyst: Benzoylation of diphenyloxide with benzoic anhydride, RSC Adv. 6 (2016). doi:10.1039/c6ra05379c.

[43] Y. Ding, Q. Gao, G. Li, H. Zhang, J. Wang, L. Yan, J. Suo, Selective epoxidation of cyclohexene to cyclohexene oxide catalyzed by Keggin-type heteropoly compounds using anhydrous urea-hydrogen peroxide as oxidizing reagent and acetonitrile as the solvent, J. Mol. Catal. A Chem. 218 (2004) 161-170. doi:10.1016/j.molcata.2004.04.019.

[44] Z. Mohammadbagheri, A. Najafi Chermahini, KCC-1/Pr-SO3H as an efficient 
heterogeneous catalyst for production of n-butyl levulinate from furfuryl alcohol, J. Ind. Eng. Chem. 62 (2018) 401-408. doi:10.1016/j.jiec.2018.01.020.

[45] T. Baba, H. Watanabe, Y. Ono, Generation of acidic sites in metal salts of heteropoly acids, J. Phys. Chem. 87 (1983) 2406-2411. doi:10.1021/j100236a033.

[46] S. Banerjee, K.K. Kar, Aluminum-substituted phosphotungstic acid/sulfonated poly ether ether ketone nanocomposite membrane with reduced leaching and improved proton conductivity, High Perform. Polym. 28 (2016) 1043-1058.

doi:10.1177/0954008315614984.

[47] N.K. Lazaridis, D.D. Asouhidou, Kinetics of sorptive removal of chromium(VI) from aqueous solutions by calcined Mg-Al-CO3 hydrotalcite, Water Res. 37 (2003) 28752882. doi:10.1016/S0043-1354(03)00119-2.

[48] N. Déchamp, A. Gamez, A. Perrard, P. Gallezot, Kinetics of glucose hydrogenation in a trickle-bed reactor, Catal. Today. 24 (1995) 29-34. doi:10.1016/09205861(95)00019-C.

[49] J.N. Appaturi, M.R. Johan, R.J. Ramalingam, H.A. Al-Lohedan, J.J. Vijaya, Efficient synthesis of butyl levulinate from furfuryl alcohol over ordered mesoporous Ti-KIT-6 catalysts for green chemistry applications, RSC Adv. 7 (2017) 55206-55214. doi:10.1039/C7RA10289E. 